\title{
FAKTOR KEGAGALAN PEMEKARAN KECAMATAN MANDAU KABUPATEN BENGKALIS MENJADI DAERAH OTONOM ERMAN EPISABRI
}

Jurusan Ilmu Politik, Fakultas Ilmu Sosial dan Ilmu Politik, Universitas Andalas Email: ermansabri99@gmail.com

\begin{abstract}
Abstrak
Faktor Kegagalan Pemekaran Kecamatan Mandau Kabupaten Bengkalis Menjadi Daerah Otonom memperlihatkan bahwa, adanya berbagai penghambat untuk daerah tersebut mendapatkan status sebagai Daerah Otonomi Baru di Riau. Pada dasarnya persoalan yang jadi penghambat tersebut ialah, persoalan regulasi yang berkepanjangan dan sekaligus ada upaya dari Kabupaten Bengkalis menghalangi Kecamatan Mandau. Unsur politik tidak terelakkan dengan mempengaruhi elit-elit yang notabenenya pejuang Kecamatan Mandau ini dengan berbagai posisi jabatan guna untuk membungkam aktor-aktor pejuang pemekaran tersebut. Kecamatan Mandau merupakan sebuah daerah yang memiliki sumber daya alam yang berlimpah, sehingga pada usulan pemekaran daerah ini terjadi tarik ulur antara pemerintah daerah dengan masyarakat yang menginginkan pemekaran tersebut. Usulan pemekaran ini sudah berlangsung sejak lama, dimulai pada tahun 1997, proses memanas puncaknya pada tahun 2007 hingga saat ini.
\end{abstract}

Kata Kunci : Pemekaran, Aktor, Daerah Otonom

\begin{abstract}
Failure Factors for Expansion of Mandau Subdistrict, Bengkalis District to Become Autonomous Regions shows that, there are various obstacles for the area to get status as the New Autonomous Region in Riau. Basically the problem that becomes the obstacle is, the problem of prolonged regulation and at the same time there are efforts from Bengkalis Regency to obstruct Mandau District. The political element is inevitable by influencing the elites who incidentally fighters of the Mandau Subdistrict with various positions in order to silence the pemekaran actors. Mandau Subdistrict is an area that has abundant natural resources, so that in the proposed expansion of this region there is a tug of war between the regional government and the people who want the expansion. This proposed expansion has been going on for a long time, starting in 1997, the process of heating up its peak in 2007 to the present.
\end{abstract}

Keywords : Expansion, Actors, Autonomous Region

\section{PENDAHULUAN}

Sejak diterapkannya moratorium tentang pemekaran daerah, tuntutan terhadap munculnya daerah otonomi baru terus meningkat. Padahal pemerintah berdasarkan keputusan Kementerian Dalam Negeri telah menerapkan moratorium untuk mengkaji lebih dalam terkait pemekaran daerah. Berdasarkan keputusan tersebut, bahwa pemekaran telah dihentikan, tetapi banyak daerah tetap menginginkan agar dapat menjadi daerah otonom, karena banyak keuntungan-keuntungan yang didapatkan. ${ }^{1}$ Beberapa daerah sudah

\footnotetext{
${ }^{1}$ Sebanyak 314 usulan Daerah Otonomi Baru (DOB), namun prinsip moratorium yang dikeluarkan pemerintah bertujuan untuk agar daerah tidak asal dimekarkan, tapi harus dikaji secara mendalam, karena anggaran untuk pemekaran suatu daerah sangatlah besar.
} 
menunjukkan keberhasilan usulan pemekaran daerahnya seperti, Kota Tangerang Selatan (Banten), Kab Tambrauw (Papua Barat), Kab Siak.Sedangkan di Riau isu tentang pemekaran kabupaten/kota sudah mulai mendapatkan perhatian, misalnya isu pemekaran Kecamatan Mandau menjadi daerah otonom. Bahkan tidak hanya itu, pemekaran terkait dengan wacana membentuk provinsi daerah Riau Pesisir juga muncul dalam perdebatanperdebatan para aktivis. Kajian tentang pemekaran tidak banyak mendapat perhatian dari para ilmuan. Kimura (2006, 2007,2010) menelisik isu pemekaran dengan menggunakan pendekatan politik yang ia sebut "vertical coalitions" untuk menyoroti motivasi dan proses politik yang mengiringi aspirasi pemekaran. Menurut Kimura, faktor koalisi/aliansi politik vertikal antar berbagai jaringan memberikan pengaruh bagi keberhasilan aspirasi pemekaran. $^{2}$

Sedangkan penjelasan yang bersifat pragmatis, Makaganza memahami pemekaran daerah sebenarnya dipakai sebagai upaya memperhalus bahasa (eupieisme) yang menyatakan proses "perpisahan" atau 'perpecahan' satu wilayah untuk membentuk satu unit administrasi lokal baru. Dilihat dari filosofi harmoni, istilah perpisahan atau perpecahan memiliki makna yang negatif sehingga istilah pemekaran ${ }^{3}$ daerah dirasa lebih cocok digunakan untuk menggambarkan proses terjadinya daerah-daerah otonom baru pasca reformasi di Indonesia.

Kronologis pemekaran Kecamatan Mandau yang mengalami tarik ulur dalam kurun waktu kurang lebih 20 tahun ini, juga beriringan dengan 4 empat kali perubahan UndangUndang tentang pemerintahan daerah. Yaitu, pertama Undang-Undang Nomor 22 Tahun 1999, Undang-Undang Nomor 32 Tahun 2004, Undang-Undang Nomor 78 Tahun 2007 dan terakhir Undang-Undang Nomor 23 Tahun 2014. Dari keempat perubahan Undang-Undang tentang pemerintahan daerah tersebut, mewarnai proses usulan pemekaran Kecamatan Mandau. Namun, setelah peneliti telusuri, seiring dengan perubahan tersebut, yang menjadi penghambat Kecamatan Mandau menjadi Kabupaten ialah terkait persyaratan mengenai cakupan kewilayahan yang tidak mencukupi sesuai Undang-Undang. Istilah pemekaran merupakan salah satu hasil dan citra positif era reformasi, dengan menata kembali UndangUndang Pemerintahan Daerah No. 23 Tahun 2014 dengan mengedepan keadaban dalam menjaga kesatuan dan persatuan. ${ }^{4}$

Secara umum, pembentukan daerah persiapan sebagaimana yang dimaksud dalam Pasal 33 Ayat (1) UU No. 23 Tahun 2014, harus memenuhi 2 (dua) persyaratan, yaitu persyaratan pertama, persyaratan dasar yang dimana persyaratan dasar terbagi atas persyaratan dasar kewilayahan yang meliputi luas wilayah minimal, jumlah penduduk

\footnotetext{
${ }^{2}$ Panji Anugrah Permana. Evaluasi Terhadap Pemekaran Daerah Dan Potensi Penggabungan Daerah (Kasus Kabupaten Sigi dan Kabupaten Tanjung Jabung Timur), PT. Balai Pustaka (Persero), Jakarta Timur, 2016. Hlm.4

3 Istilah pemekaran untuk memperhalus bahasa, maka disebut sebagai proses "perpisahan"atau 'perpecahan' pada suatu wilayah (Makaganza, 2008:9)

4 Djoko Harmantyo, Pemekaran Daerah dan Konflik Keruangan Kebijakan Otonomi Daerah dan Implementasinya di Indonesia, Departemen Geografi FMIPA, Universitas Indonesia: Jurnal Makara Sains, Volume 11, No.1 April 2007, Hlm 23-35
} 
minimal, batas wilayah, cakupan wilayah, batas usia minimal daerah provinsi, daerah kabupaten/kota, dan kecamatan.

Persyaratan dasar kedua yang harus dipenuhi adalah persyaratan kapasitas daerah yang meliputi: 1) Geografi, 2) Demografi, 3) Keamanan, 4) Sosial politik, adat istiadat, dan tradisi, 5) Potensi ekonomi, 6) Keuangan daerah, 7) Kemampuan penyelenggaran pemerintahan. ${ }^{5}$

Permintaan dari kalangan masyarakat Mandau agar dapat dijadikan daerah otonom yang baru bukan tanpa dasar, mereka sangat percaya diri akan potensi yang dimiliki oleh Duri selama ini. Di mana di daerah ini terdapat beberapa perusahaan besar yang mampu mendongkrak daerah ini kearah kemajuan. Di Kecamatan Mandau khususnya Duri terdapat beberapa perusahaan minyak yang cukup terkenal di Indonesia. Seperti PT.Chevron Pacific Indonesia (CPI), bersama Minas dan Dumai, Duri menyumbang sekitar $60 \%$ produksi minyak mentah Indonesia, dengan rata-rata produksi saat ini 400.000-500.000 barel per hari. ${ }^{6}$ Namun proses tersebut sering menemukan hambatan, terutama yang berkaitan dengan pemerintah Kabupaten Bengkalis.

Peneliti melihat bahwa ada andil besar pemerintahan Kabupaten Bengkalis agar daerah ini tidak dimekarkan karena bagi hasil dari daerah ini cukup besar bagi pendapatan daerah. Hal ini didasarkan pada opini yang tersebar dan terdengar dalam perbincangan masyarakat sehari-hari. Tidak hanya masyarakat Kecamatan Mandau, opini ini juga muncul di seluruh penjuru Provinsi Riau.

Namun, setelah melalui beberapa gejolak ditengah-tengah masyarakat, akhirnya usulan pemekaran ini sampai ke Senayan. Tetapi upaya ini terhenti karena persyaratan administrasi yang tidak mencukupi.

Sementara untuk ketiga Rancangan Undang-Undang yang lain termasuk Rancangan Undang-Undang Pembentukan Kabupaten Mandau untuk sementara belum bisa disepakati dan akan dibahas lebih lanjut dalam persidangan berikutnya dengan catatan untuk Rancangan Undang-Undang tentang Pembentukan Kabupaten Mandau di Provinsi Riau. Komisi II DPR-RI mengharapkan kepada Pemerintah Kabupaten Bengkalis dan Pemerintah Provinsi Riau untuk melengkapi persyaratan administrasi dan fisik kewilayahan khususnya penambahan cakupan wilayah calon Kabupaten Mandau. Oleh karena itu, Komisi II DPRRI berharap kepada provinsi dan kabupaten induk untuk segera melengkapi persyaratan administrasi, syarat teknis khususnya yang berkaitan cakupan wilayah sesuai dengan peraturan perundang-undangan yang berlaku. ${ }^{7}$

\footnotetext{
5 H. Kambuno. Pemekaran Daerah Berdasarkan Undang-Undang Nomor 23 Tahun 2014 Tentang Pemerintahan Daerah. Journal. Neliti.com. Vol 1. No.1. April 2012. Hlm. 6-8

6 Andre Setiawan, "Ribuan Orang Demo Pemekaran Wilayah Kota Duri Riau Lumpuh", (https://news.detik.com Juni 12 2008) diakses pada tanggal 12 September 2018, Pukul 23:08 WIB

${ }^{7}$ M.Zaunuddin, Partisipasi Politik: Kajian Rencana Pemekaran Kabupaten Mandau dari
} 
Hingga kini, kurang adanya keseriusan dari elemen masyarakat untuk mengusut tuntas persoalan ini, sehingga hanya menjadi isu hangat ketika tahun-tahun politik.fenomena saat ini menjelang pemilu banyak kandidat yang berkampanye di Kecamatan Mandau berjanji akan memperjuangkan pemekaran daerah ini, namun hingga kini daerah tersebut masih tetap jalan ditempat di bawah naungan Kabupaten Bengkalis

\section{Konsep Pemekaran Daerah}

Konsep koalisi vertikal yang diajukan Kimura mencoba menyatukan dikotomi soal ide pemekaran datang dari bawah/bottom up atau inisiatif dari atas/top down. Kerangka kerja koalisi vertikal adalah koalisi dimana baik individu atau pun kelompok pada level administrasi yang berbeda sebagai kekuatan sentral mewujudkan pemekaran daerah. Poin sentral dari konsep yang diajukan Kimura adalah pembentukan daerah pemekaran baru bukanlah produk dari aktor tunggal atau pun sekelompok aktor. ${ }^{8}$ Tetapi merupakan usaha bersama antara individu-individu dan kelompok-kelompok pada level administrasi yang berbeda-beda.

Meskipun pemekaran adalah hal yang penting namun pemekaran adalah sebuah fenomena yang belum memiliki teorinya sendiri. Untuk menjangkau fenomena ini secara teoritis banyak digunakan pendekatan ekonomi politik, Kerangka kerja koalisi vertikal ini didasarkan pada proses-proses dan relationship dalam rangka untuk memahami kemunculan fenomena pemekaran daerah di Indonesia. Kerangka kerja ini menggaris bawahi bagaimana faktor nasional dan lokal mempengaruhi cara aktor berpikir tentang daerahnya dan bagaimana, dalam kondisi yang pasti, sejumlah kepentingan aktor bisa tumpang tindih untuk membentuk koalisi vertikal demi mewujudkan status kabupaten baru.

Koalisi vertikal didefnisikan sebagai aliansi dari berbagai aktor mulai dari level lokal (kabupaten), provinsi, sampai level nasional. Actor-aktor utama dalam koalisi ini termasuk organisasi masyarakat sipil lokal, elit politik lokal, elit politik tingkat provinsi, elit politik nasional, partai politik, lembaga negara termasuk militer dan kementerian terkait. Sebuah aliansi memiliki kepentingan antara aktor yang kemungkinan tidak akan bertemu dan bekerja sama jika bukan karena pemekaran daerah. Untuk mengkaji aktor-aktor dalam koalisi ini, kita bagi menjadi tiga level administrasi, aktor lokal, tingkat provinsi dan nasional. Inisiatif tentang wacana pemekaran bisa datang dari nasional (top-down) atau dari tingkat lokal (bottom-up), dan bisa jadi secara serempak dari atas kebawah.

\section{METODE PENELITIAN}

Penelitian menggunakan metode kualitatif dengan tipe studi kasus deskriptif untuk menjelaskan dan menganalisis apa faktor-faktor masyarakat Mandau memekarkan diri menjadi daerah otonom, dan menjelaskan dan menganalisis proses pemekaran yang dilakukan oleh Kecamatan Mandau Kabupaten Bengkalis. Metode kualitatif menurut

\footnotetext{
${ }^{8}$ Ehito Kimura, Provincial Proliferatio: Vertical Coalitions And The Politics of Territoriality In Post Authoritarian Indonesia,(Disertasi Political Science University of Wisconsin-Madison , 2006).Hlm.15
} 
Creswell melakukan framing atau sudut pandang perilaku manusia dan keyakinan dalam sosial-politik-histori. ${ }^{9}$

Dalam memilih analisis studi kasus peneliti memiliki alasan karena penelitian mengenai faktor pemekaran Kecamatan Mandau Kabupaten Bengkalis menjadi daerah otonom ini dirasa unik karena, dilihat dari jalannya roda pemerintahan Kabupaten Bengkalis, sepertinya tidak ada masalah yang muncul. Akan tetapi ketika peneliti mencari data-data di media online mengenai isu upaya pemekaran ini, isu-isu ini cukup memanas dalam kancah media internet online. Selain itu, isu ini juga memanas di kalangan masyarakat awam dan telah lama menjadi perbincangan. Bertolak belakang sekali dengan pemerintah Kabupaten Bengkalis yang secara tidak langsung, sama sekali tidak menghiraukan isu ini.

Pada dasarnya penelitian dengan jenis studi kasus bertujuan untuk mengetahui tentang sesuatu hal secara mendalam. Maka dalam penelitian ini, peneliti akan menggunakan metode studi kasus untuk mengungkap faktor-faktor apa saja yang membuat masyarakat Mandau ingin memekarkan diri menjadi daerah otonom.

\section{HASIL DAN PEMBAHASAN}

Pemekaran daerah di Provinsi Riau sangat bergantung pada Undang-Undang pemerintahan daerah, ini terkait dengan persyaratan yang harus dipenuhi oleh daerah pemekaran. Misalnya pemekaran Kecamatan Mandau untuk menjadi daerah otonom dan melepaskan diri dari Kabupaten Bengkalis sebagai kabupaten induk. Kegagalan kecamatan Mandau ini adalah bagian dari persoalan pemekaran yang terus mengemuka di Provinsi Riau.

Usulan pemekaran Kecamatan Mandau ini dimulai dari level bawah ke atas (Bottom Up) atau dari level atas ke bawah (Top Down) sesuai dengan konsep Kimura yang digunakan oleh peneliti. Elit di tingkat lokal, tokoh masyarakat, dan masyarakat setempat turut berperan aktif didalam usulan pemekaran. Seperti yang dijelaskan oleh Hamka Riau, beliau merupakan ketua KP2KM, dengan kutipan wawancara berikut ini :

Usulan pemekaran ini dari lapisan bawah ya (Bottom Up), meliputi masyarakat, para tokoh masyarakat, pemuda juga, ormas terkait. Kemudian barulah mendapatkan dukungan dari elit-eit di atas (Top Down). ${ }^{10}$

Selain itu penelitian ini mengelompokkan beberapa faktor kegagalan pemekaran Kecamatan Mandau menjadi daerah otonom, berikut ini :

\footnotetext{
${ }^{9}$ Creswell, J. w. 2007. Research Design, Qualitative, Quantitative, and Mixed Methods Approaches. UK: SAGE Publication Inc. hlm 14

${ }^{10}$ Wawancara dengan Hamka Riau, Ketua Komite Pembentukan Pemekaran Kabupaten Mandau , Pada 20 Mei 2019 di Kediaman Hamka Riau Jln. Sudirman RT/RW 001/006 Desa Simpang Padang Kecamatan Mandau, Bengkalis.
} 


\section{Persyaratan Administrasi}

Kecamatan Mandau ketika mengusulkan diri menjadi kabupaten, tidak memenuhi persyaratan yang mengharuskan lima kecamatan. Walaupun di unsur-unsur lain kecamatan Mandau ini sudah memenuhi kriteria, seperti jumlah penduduk, perkembangan daerah yang meliputi pusat-pusat perbelanjaan, perkantoran sudah sangat maju pesat sekali. Hal ini juga dijelaskan oleh Khairul Umam, berikut ini :

Iya sebenarnya sudah sampai di Senayan, namun ditolak karena terkendala oleh regulasi undang-undang tentang pemerintahan daerah, dahulu itu hanya memiliki dua (2) kecamatan, tentunya tidak bisa menjadi kabupaten. ${ }^{11}$

Hal ini sesuai dengan regulasi undang-undang Nomor 32 Tahun 2004 dan undang-undang Nomor 23 Tahun 2014, yang mensyaratkan untuk menjadi kabupaten harus memiliki lima (5) kecamatan dan menjadi kota 3 (tiga) kecamatan.

\section{Visi Antar Elit Berbeda}

Salah satu faktor dari kegagalan pemekaran kecamatan Mandau kabupaten Bengkalis yang peneliti menemukan penjelasan di lapangan, bahwa memang visi anta elit berbeda khususnya para pejuang, tidak memiliki pemikiran dan tujuan yang sama, ada yang sepakat dijadikan kabupaten dan ada yang menolak. Kemudian ada yang sepakat dijadikan kota madya ada juga yang menolak. Jadi fenomena ini memiliki relevansi dengan teori yang peneliti gunakan yaitu teori yang dikemukakan oleh Kimura (Vertical Coalitions). Hal ini juga dijelaskan oleh Amat. S, berikut ini :

Elit disini saja tidak memiliki visi yang sama, asal sudah dapat saja jabatan dari kabupaten induk, maka diamlah. Selain itu, sikap pro-kontra menjadi kota juga terjadi, kami suku sakai Mandau ini tidak mendapat informasi terkait kota. $^{12}$

Dengan demikian, jika visi elit kecamatan Mandau ini kedepannya masih mengedepankan egoisme masing-masing maka pemekaran ini hanyalah wacana belaka.

\section{Relasi Elit Lemah}

Hingga hari ini, elit politik Riau ditingkat nasional terbilang lemah. Oleh sebab itu, yang terjadi di kecamatan Mandau ini, memiliki relevansi dengan teori (Vertical Coalitions) yang peneliti gunakan. Hal ini juga dijelaskan oleh, H. Musri berikut ini :

Jadi memang elit politik kita riau ini memang lemah, ditambah dengan kepala daerah tidak setuju, jadi bagaimana lagi kami mengupayakan, inilah kacau

\footnotetext{
11 Wawancara dengan Khairul Umam, Ketuan DPD Partai Keadilan Sejahtera (PKS) Kabupaten Bengkalis, Pada 23 Juni 2019 di Mandau, Bengkalis.

12 Wawancara dengan Amat S, Ketua Suku Sakai Kecamatan Mandau, Pada 28 Juni 2019 di Jln. Damai, Desa Pinggi Kecamatan Pinggir.
} 
buruknya penguasa, tidak mau membagi kekuasaan. Kami seolah-seolah tidak mau berbuat baik kepada masyarakat disini.

Dengan demikian, selagi elit politik kecamatan Mandau, Riau pada umumnya, jika tetap tidak memiliki relasi politik yang kuat, maka pemekaran ini hanya menjadi agenda nihil hasilnya. Kalau pun persyaratan sudah terpenuhi, jika proses lobbying yang tidak kuat, maka sulit untuk terwujud, karena juga banyak daerah yang ingin mekar.

\section{Terkendala Oleh Moratorium}

Salah satu faktor kegagalan pemekaran kecamatan Mandau ini saat pengajuan sebagai kota Madya Duri memang terkendala oleh moratorium oleh pemerintah pusat. Hal tersebut juga peneliti temukan di lapangan, bahwa memang moratorium menjadi penghambat saat ini, hal ini dijelaskan oleh $\mathrm{H}$. Arwan, dengan kutipan berikut ini : ${ }^{13}$

Salah satu faktor kegagalan pemekaran Kecamatan Mandau adalah karena moratorium yang dikeluarkan oleh pemerintah jokowi.

Moratorium menjadi bagian gagalnya pemekaran kecamatan Mandau, namun dibalik itu sebenarnya terdapat proses yang bertele-tele sehingga hadirlah moratorium sejak era pemerintahan Jokowi-Jk.

\section{Sebagai Daerah Abu-Abu Saat Pemilu}

Sepanjang sejarah kabupaten Bengkalis, bupati yang berasal dari Bengkalis daratan baru lah Amril Mukminin yang notabenenya adalah putra asli Mandau. Dengan maju Amril Mukminin sebuah harapan dari semua masyarakat kecamatan Mandau menemukan titik terang, harapan menjadi daerah otonom yang baru mendapatkan sinyal positif. Namun berbanding terbalik, berdasarkan temuan peneliti di lapangan bahwa putra asli Mandau yang memimpin kabupaten Bengkalis saat ini menjadi tidak mampu membantu daerah ini untuk menjadi daerah otonomi baru dan saat ini Amril Mukminin sudah ditetapkan sebagai tersangka oleh Komisi Pemberantasan Korupsi. Hal ini dijelaskan oleh Agung Marsudi, berikut ini : ${ }^{14}$

Terkait janji politik ini, teradapat broker-broker untuk dapat duet sebagai jualan politik. Tentunya janji tingga janji begitulah, dari pemilu ke pemilu ya begiru terus, bahan lama yang masih di lestarikan.

Teori desentralisasi dan pemekaran wilayah terdapat dimensi-dimesi pemekaran, pelaku dan peran aktor dalam pemekaran, alasan dan motif pemekaran. Dengan

\footnotetext{
${ }^{13}$ Wawancara dengan Arwan Mahidin R, Tokoh Masyarakat Kecamatan Mandau, Pada 20 Mei 2019 di Kediamannya Jln. Satria Kecamatan Mandau, Bengkalis.

${ }^{14}$ Wawancara dengan Agung Marsudi, Pengamat Politik Sekaligus Jurnalis Yang Menyoroti Usulan Pemekaran Kecamatan Mandau, Pada 20 Mei 2019 di Mandau, Bengkalis.
} 
demikian, janji politik terkait pemekaran hanya dijadikan sebagai Political Will pada saat momentum pemilu saja. ${ }^{15}$

Dengan dijadikan sebagai daerah abu-abu didalam politik praktis, peneliti berasumsi hal ini akan berlangsung lama, karena para elit politik baik pilkada dan pileg daerah ini akan terus dijadikan objek untuk memperoleh dukungan, karena jumlah penduduk yang begitu besar. Hal ini sudah terjadi di tiga bupati yang memimpin kabupaten Bengkalis dalam kurun waktu kurang lebih 20 tahun.

\section{Bagi Hasil Kecamatan Mandau Untuk Membangun Kecamatan Lain}

Dengan sumbangsih yang didapat oleh pemerintah Kabupaten Bengkalis dari kecamatan Mandau sekitar 60\% pertahun, membuat Bengkalis enggan melepas kecamatan Mandau berdiri sendiri. Hal ini dikarenakan penghasilan bagi anggaran daerah yang diperoleh begitu besar setiap tahunnya. Sehingga pemerintah kabupaten bersama DPRD kabupaten Bengkalis meminta kepada pihak pengusul untuk bersabar terlebih dahulu karena terdapat beberapa kecamatan yang jauh dari kesejahteraan dan terbelakang dalam hal pembangunan.

Berdasarkan argumentasi tersebut, peneliti mendapatkan penjelasan di lapangan, dari Indra Sukmana, beliau menyampaikan meminta kepada masyarakat Kecamatan Mandau untuk bersabar terlebih dahulu, dengan kutipan wawancara berikut $:^{16}$

Kami sebenarnya ya meminta kepada pengusul pemekaran ini untuk bersabar dulu, karena apa, masih banyak kecamatan-kecamatan lain yang masih tertinggal pembangunannya. Seperti contoh, kecamatan Rupat dan Rupat Utara, saudara kita disana masih jauh pembangunannya. Itulah yang dilakukan peemrintah saat ini, bagaimana kecamatan tertinggal itu bisa dibangun dahulu. Jadi dengan banyaknya dana yang didapat dari Mandau ini menjadi sumber yang besar bagi pemerintah untuk membangun daerah tertinggal, jadi ya sabarlah dulu.

Dalam konteks konsep (Vertical Coalitions) dikenal dengan pendekatan ekonomi, hal ini relevan dengan fenomena di kecamatan Mandau. selain itu, dilihat dari alasan dari pemerintah daerah, dengan dalih peran serta kecamatan Mandau didalam membangun kecamatan lain masih diperlukan. Pendekatan ekonomi ini juga banyak dilakukan dalam kajian-kajian terkait pemekaran daerah.

\footnotetext{
${ }^{15}$ Akhpriyani Trisnawati, Fitriyah, Budi Setiyono. Analisis Peran Aktor Dalam Pemekaran kabupaten Brebes. Journal Of Politic and Goverment Studies. Vol. 4 No. 2. HIm. 26-50

${ }^{16}$ Wawancara dengan Indra Sukmana, Anggota Lagislatif Dewan Perwakilan Rakyat Daerah (DPRD) Bengkalis, Pada 24 Juni 2019 . di Kantor DPRD Jln. Hang Tuah. No.07 . Bengkalis.
} 


\section{Identitas Kemelayuan Terancam Hilang}

Riau merupakah negeri lancang kuning, dalam sejarah tempat berdirinya kerajaan melayu yang memiliki pengaruh kuat pada NKRI. Berstatus kerajaan Riau merupakan negeri yang kaya akan sumber daya alam, tanah bertuah sejak masa kesultanan. Sumbangsih kerajaan siak untuk kemerdekaan Republik Indonesia yang diserahkan oleh Sultan Syarif Kasyim II kepada proklamator kita sebesar 16.000 golden menjadi titisan sejarah yang amat membanggakan bagi orang melayu Riau saat ini. Selain itu, politik orang melayu Riau dikenal menganut istilah "politik identitas" yang kuat, keinginan pemimpinnya juga harus dari suku melayu berlangsung hingga saat ini. terkait hal ini juga dijelaskan oleh Hamka Riau, berikut ini : ${ }^{17}$

Berbagai alasan-alasan seperti jika Mandau mekar, Bengkalis akan tertinggal, yang akan menjadi bupati nanti bukan orang melayu, mayoritas disinikan memang pendatang, itulah ketakutannya, dan alasan klasik itu terus dibunyikan, terus digaungkan.

Selain itu, terkait identitas kemelayuan ini, memiliki relevansi dengan teori (Perubahan Sosial) yang dikemukakan oleh Khaldun, mendefinisikan perubahan sosial bisa terjadi karena berbagai variasi dari cara hidup yang diterima, seperti kebudayaan material. Dengan hal ini, membuat identitas masyarakat kecamatan Mandau yang notabenenya ialah melayu dikhawatirkan akan hilang dengan banyaknya etnis dan budaya non-melayu yang tinggal di kecamatan Mandau.

\section{Penyebaran Agama Tertentu}

Ada pun yang melatarbelakangi persoalan ini ialah dapat dilihat dari persentase agama penduduk Kecamatan Mandau yaitu, Islam 50\%, Kristen 20\%, Kong $\mathrm{Hu} \mathrm{Cu} 10 \%$ dan Budha 20\%. Penduduk Kecamatan Mandau saat ini memang sudah heterogen dalam sosial masyarakat. hal ini juga didasari oleh banyaknya pendatang yang bekerja dan menetap di Kecamatan Mandau. Selain itu, merupakan Political Will pemerintah Kabupaten Bengkalis untuk agar bagaimana pemekaran ini gagal. Hal ini dijelaskan oleh Arwan Mahidin berikut ini : ${ }^{18}$

Faktor lain yaitu isu yang di mainkan yaitu sosial budaya, agama, bahkan beredar kabar akan berdiri rumah ibadah agama tertentu terbesar di Asia Tenggara. Itu yang dimainkan sampai ke Jakarta. Rukun antar umat beragama disini kami sudah biaso, cumo itulah isu yang dimainkan oleh pihak yang tak mau Mandau ini mekar.

\footnotetext{
17 Wawancara dengan Hamka Riau, Ketua Komite Pembentukan Pemekaran Kabupaten Mandau, Pada 20 Mei 2019 di Kediaman Hamka Riau Jln. Sudirman RT/RW 001/006 Desa Simpang Padang Kecamatan Mandau, Bengkalis.

${ }^{18}$ Wawancara dengan Arwan Mahidin R, Tokoh Masyarakat Kecamatan Mandau, Pada 20 Mei 2019 di Kediamannya Jln. Satria Kecamatan Mandau, Bengkalis.
} 
Isu agama memang dimainkan oleh pihak yang menginginkan pemekaran ini gagal dengan melihat jumlah rumah ibadah agama tertentu yang berdiri di kecamatan Mandau ini. Isu penyebaran agama tertentu juga berkaitan dengan teori Perubahan Sosial, Khaldun juga menjelaskan bahwa perubahan sosial juga didasarkan oleh ideologi ${ }^{19}$ yang dianut, oleh sebab itu isu yang berkaitan dengan penyebaran agama tertentu ini bisa menjadi alasan agar kecamatan Mandau ini gagal menjadi daerah otonom.

\section{KESIMPULAN}

Tidak mengherankan jika masih banyak daerah yang menginginkan daerah otonom baru, namun terganjal oleh beberapa hal, mulai dari level bawah (Bottom Up) hingga ketingkat atas (Top Down) yang menjadi penghambat, terutama yang berkaitan dengan keinginan kabupaten induk untuk melepas daerah yang menjadi cakupan wilayahnya. Selain itu, pemekaran daerah juga kerap kali terhalang oleh syarat yang terdapat pada Undang-Undang tentang pemerintahan daerah.

\section{DAFTAR PUSTAKA}

Afrizal. 2014. Metode Penelitian Kualitatif: Sebuah Upaya Mendukung Penggunaan Penelitian Kualitatif Dalam Berbagai Disiplin Ilmu. Jakarta. Penerbit Rajawali Pers.

Ehito Kimura. 2006. Provincial Proliferatio: Vertical Coalitions And The Politics of Territoriality In Post Authoritarian Indonesia. Disertasi Political Science University of Wisconsin-Madison.

J.W. Creswell. 2007. Research Design, Qualitative, Quantitative, and Mixed Methods Approaches. UK: SAGE Publication Inc.

Mungin, Burhan Mungin. 2012. Metodologi Penelitian Kualitatif. Jakarta. PT. Raja Grafindo Persada.

Mardalis. 2006. Metode penelitian suatu pendekatan proposal. Penerbit Bumi Aksara. Jakarta.

Permana Anugrah Panji. 2016. Evaluasi Terhadap Pemekaran Daerah Dan Potensi Penggabungan Daerah (Kasus Kabupaten Sigi dan Kabupaten Tanjung Jabung Timur). Jakarta Timur. Penerbit PT. Balai Pustaka (Persero).

Sugiyono. 2012. Metode Penelitian Kuantitatif, Kualitatif, Dan R\&D. Penerbit Bandung : Alfabeta.

Yin. K. Robert. 2009. Case Study Research Design and Methods, 3rd ed. Sage, ThousandOaks, CA.pdf. California: SAGE Publication Inc.

\footnotetext{
${ }^{19}$ Ibid. Hal. 77
} 
Andik Wahyun Muqoyyidin Wahyunun Andik.2010. Pemekaran Wilayah dan Otonomi Daerah Pasca Reformasi di Indonesia: Konsep, Fakta Empiris, dan Rekomendasi Ke Depan. Jurnal Konstitusi. neliti.com. 6(1): Hlm. 137

Alipania. 2013. Pemekaran Daerah Dan Implikasinya Terhadap Pelaksanaan Otonomi Daerah Di Sumatera Utara. Jurnal Ilmu Hukum dan Humaniora. 1(1):1-16

Argama R. 2005. Pemberlakuan Otonomi Daerah dan Fenomena Pemekaran Wilayah di Indonesia. Fakultas Hukum. jdih.sumselprov.go.id. 3(1) : 32-78

Ervianto Tedi, Bandiyah, dan Remiman, 2017. Pengaruh Elit Terhadap kegagalan Otonomi Daerah di Kabupaten Nias Utara. E-Jurnal Politica.1. (12 ): Hlm. 1-9

Haryanto. 2016. Masa depan Politik Desentralisasi Di Indonesia: Sebuah Studi Awal. Jurnal Ilmu Pemerintahan. 9(2): 116-117

Herawati Retno Nunik. 2011. Pemekaran Daerah Di Indonesia.Politika Jurnal Ilmu Politik.2(1): Hlm. 57-65

Handoyo E, Ristanti YD. 2017. Undang-Undang Otonomi Daerah dan Pembangunan Ekonomi Daerah. jurnal.untidar.ac.id. (2(2) : 13

Kambuno H.2012. Pemekaran Daerah Berdasarkan Undang-Undang Nomor 23 Tahun 2014 Tentang Pemerintahan Daerah. Journal. Neliti.com.1(1): Hlm. 6-8

Marjak Multazam, 2016. Politik Pemekaran Wilayah "Studi kasus Kegagalan Pembentukan Kabupaten Lombok Selatan Tahun 2014. ejournal3.undip.ac.id. 2(5): Hlm. 1-15

M.Zaunuddin. 2015. Partisipasi Politik: Kajian Rencana Pemekaran Kabupaten Mandau dari Kabupaten Bengkalis, Propinsi Riau.Jurnal ejournal.unri.ac.id. 14 (24): 23-40

Martono.N. 2015. Perubahan Sosial. stitjembrana.ac.id.2 (1): 1-23. 1-23

Puspitasari Ratty. 2014. Faktor-Faktor Yang Mempengaruhi Pembentukan Daerah Baru (Study Kelayakan Secara Administratif Kabupaten Indragiri Selatan). Jurnal Online Mahasiswa Fakultas Ilmu Sosial dan Ilmu Politik Universitas Riau.( 2): 210

Rahman A. Otonomi Daerah Menurut UU 23 Tahun 2014 . Journal eprints.umm.ac.id. 4.(2): $39-50$

Suratmin Dwi Surya.2014. Persepsi Masyarakat Tentang Kesejahteraan Masyarakat Desa Bagelen Kecamatan Gedongtataan Kabupaten Pesawaran Setelah Pemekaran Tahun 2012. Jurnal digilib.unila.ac.id. 9(3): 11-120

Suwaryo U. 2006 Otonomi Daerah Berdasarkan Undang-Undang Nomor 22 Tahun 1999 di Kabupaten Bandung. jurnal.unpad.ac.id. 5 (1) :145 
Trisnawati Akhpriyani, Fitriyah, Setiyono Budi. 2015. Analisis Peran Aktor Dalam Pemekaran kabupaten Brebes. Journal Of Politic and Goverment Studies. 4 (2): 26-50 